\title{
Percolation of Carbon Nanoparticles in Poly(3-Hexylthiophene) Enhancing Carrier Mobility in Organic Thin Film Transistors
}

\author{
Chang-Hung Lee, ${ }^{1}$ Chun-Hao Hsu, ${ }^{1}$ Iu-Ren Chen, ${ }^{2}$ Wen-Jong Wu, ${ }^{2}$ and Chih-Ting Lin ${ }^{1,3}$ \\ ${ }^{1}$ Graduate Institute of Electronics Engineering, National Taiwan University, Taipei 10617, Taiwan \\ ${ }^{2}$ Department of Engineering Science and Ocean Engineering, National Taiwan University, Taipei 10617, Taiwan \\ ${ }^{3}$ Department of Electrical Engineering, National Taiwan University, Taipei 10617, Taiwan
}

Correspondence should be addressed to Wen-Jong Wu; wjwu@ntu.edu.tw and Chih-Ting Lin; timlin@ntu.edu.tw

Received 3 November 2013; Revised 15 January 2014; Accepted 16 January 2014; Published 25 February 2014

Academic Editor: Chun-Hsing Shih

Copyright (C) 2014 Chang-Hung Lee et al. This is an open access article distributed under the Creative Commons Attribution License, which permits unrestricted use, distribution, and reproduction in any medium, provided the original work is properly cited.

\begin{abstract}
To improve the field-effect mobility of all-inkjet-printed organic thin film transistors (OTFTs), a composite material consisted of carbon nanoparticles (CNPs) and poly(3-hexylthiophene) (P3HT) was reported by using homemade inkjet-printing system. These all-inkjet-printed composite OTFTs represented superior characteristics compared to the all-inkjet-printed pristine P3HT OTFTs. To investigate the enhancement mechanism of the blended materials, the percolation model was established and experimentally verified to illustrate the enhancement of the electrical properties with different blending concentrations. In addition, experimental results of OTFT contact resistances showed that both contact resistance and channel resistance were halved. At the same time, X-ray diffraction measurements, Fourier transform infrared spectra, ultraviolet-visible light, and photoluminescence spectra were also accomplished to clarify the material blending effects. Therefore, this study demonstrates the potential and guideline of carbon-based nanocomposite materials in all-inkjet-printed organic electronics.
\end{abstract}

\section{Introduction}

The extensive researches of organic semiconductors have attracted considerable attention due to their potential in printed and flexible electronics. Because of the advantages of organic electronics, such as low cost, light weight, large-area manufacturing, and mechanical flexibility, these researches promote applications of organic electronics. For instance, organic thin film transistors (OTFTs) [1], solar cells [2], organic light-emitting diodes [3], and sensors [4] were proposed and implemented. In spite of these promising developments, some crucial problems have blocked the path to commercialization, such as the mobility of organic semiconductor and the feasibility of manufacturing. To address manufacturing technologies, solution processes are one of the candidates. These processes include spin coating, screen printing, gravure printing, roll-to-roll printing, and inkjet printing. Among these processes, inkjet printing has advantages of mask-less deposition, etch-free fabrication, and low material consumption $[1,5]$.
Although the inkjet printing technique can offer many advantages in applications, the electrical properties of OTFTs still need to be improved from the aspect of materials. To enhance the effective mobility of the OTFT, commonly, the self-assembled monolayers (SAM) have been used to modify the interfacial properties between the organic semiconductor, dielectric layer, and the contact electrodes [6-8]. However, the SAM technique is not adapted for the all-inkjet-printing process, because the solvent used in SAM may easily dissolve the inkjet-printed layer. On the other hand, the $\mathrm{O}_{2}$ plasma treatment can also improve the surface characteristics of the dielectric layer [9]. But the plasma would break the bonds at the dielectric surface which would drive the drain current unsaturated [10]. To address these issues, some researchers have directly printed blending composite materials to improve the electrical properties of OTFTs [11]. Blending carbon nanotubes (CNTs) and organic semiconductive polymer as an active layer can enhance the carrier mobility of OTFTs [12-15]. However, forming a homogenous suspension of the CNT-blended material needs additional 


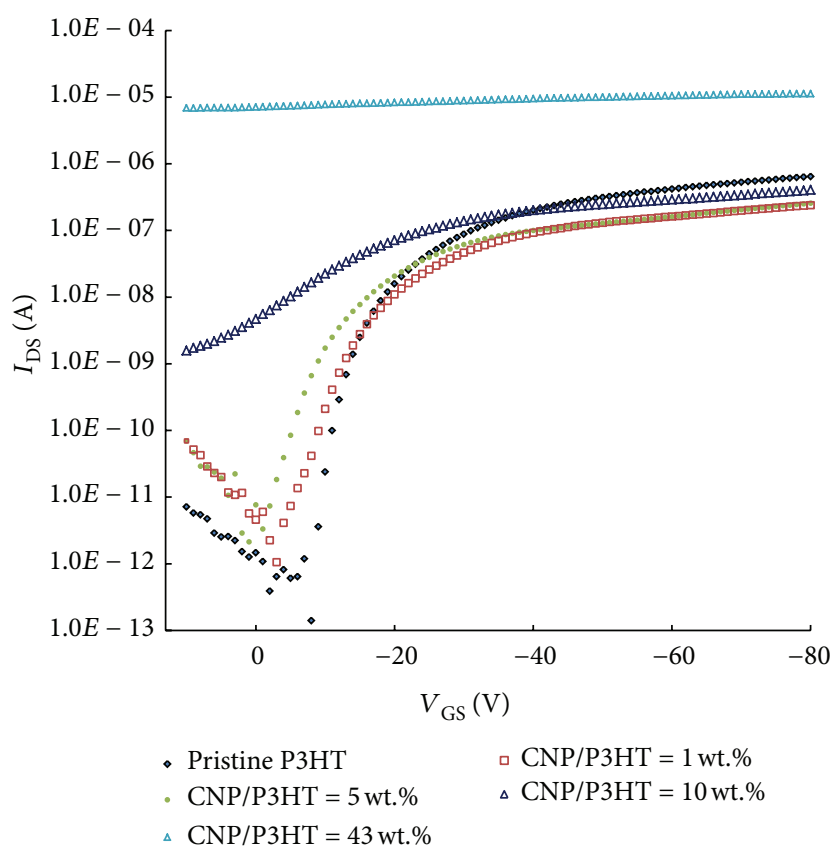

(a)

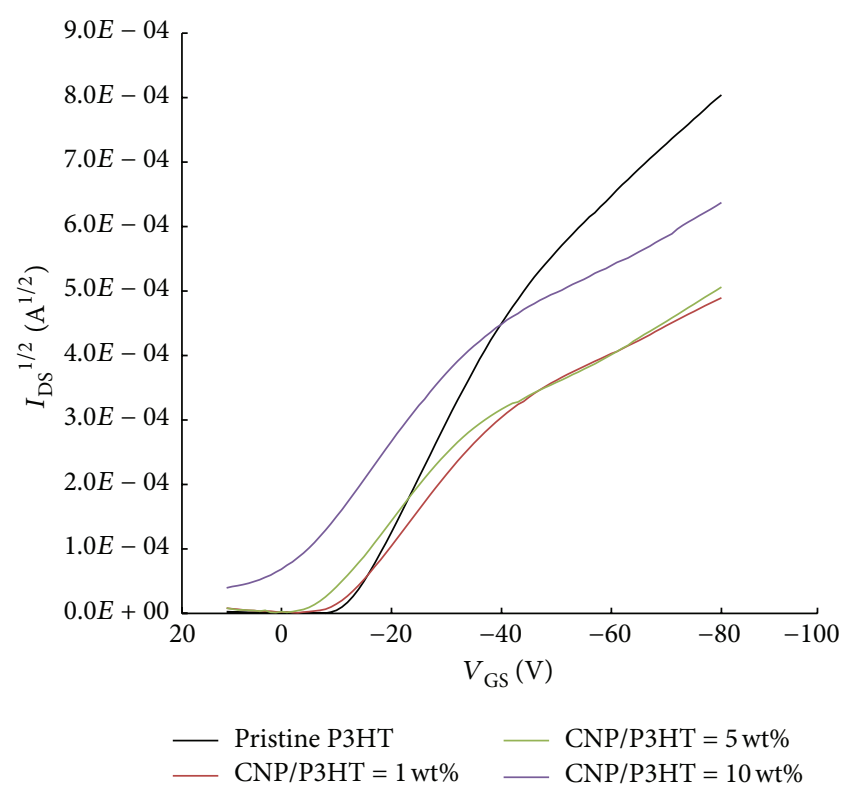

(b)

FIGURE 1: (a) $V_{\mathrm{GS}}-I_{\mathrm{DS}}$ characteristics and (b) $V_{\mathrm{GS}}-I_{\mathrm{DS}}^{1 / 2}$ characteristics of all-inkjet-printed OTFTs.

treatments such as ultrasonication or functionalized CNT. Compared with the CNTs/organic semiconductor in the previous reports, carbon nanoparticles (CNPs) could be a proper choice for inkjet printing because the CNP-blended ink has higher uniformity than CNT-blended ink does.

In this study, the OTFTs based on composite organic materials, that is, poly(3-hexylthiophene) (P3HT) blended with CNP, were fabricated to study the mobility enhancement phenomenon. In addition, a series of material analyses were accomplished to verify its characteristics. For instance, Xray diffraction (XRD) measurements were used to study the crystalline ordering in the composite film; Fourier transform infrared (FTIR) spectra were used to confirm the bonding formation between the CNP and P3HT; ultraviolet-visible light (UV-Vis) and photoluminescence (PL) spectra were conducted to explore the formation of the charge-transfer complexes (CTC). The contact resistance measurements are achieved to explore the interfaces between the electrodes and the active layer, further to study the carrier injection barrier. Based on the above analysis and the local electric field enhancement model $[13,16,17]$, the percolation theory interpreted the electrical properties of the OTFTs at the different blended CNP concentrations.

\section{Materials and Methods}

The all-inkjet-printed OTFTs were fabricated by using a homemade inkjet printing system. The fabricated OTFTs was bottom-gate, bottom-contact structure. We used $0.3 \mathrm{wt} . \%$ P3HT (Uni-Onward Corp., Taiwan), dissolved in p-xylene, as an organic semiconductor. The P3HT solution was blended with various concentrations of CNPs (Qf-Nano Tech. Co.
Ltd., Taiwan, model: QF-PHG-1P) including $1 \mathrm{wt} . \%, 5 \mathrm{wt} . \%$, 10 wt.\%, and 43 wt. $\%$ with respect to P3HT. The manufacturing process of the OTFTs is shown in detail in previous report [18]. In this study, the channel length and width are typically $20 \mu \mathrm{m}$ and $400 \mu \mathrm{m}$, respectively. However, to verify the contact resistance of OTFTs, a series of transistors was made in different channel lengths $(20,60$, and $100 \mu \mathrm{m})$, and the channel width was expanded to $800 \mu \mathrm{m}$. The electrical properties of the fabricated OTFTs were measured by using Agilent $4156 \mathrm{C}$ in a dark environment with humidity controlled (relative humidity $<25 \%$ ) in atmosphere.

To identify the material properties of the blended semiconductors, the fabricated OTFTs were analyzed by a series of methods. The solid-state UV-Vis absorption spectra were determined by using Jasco V-570 UV/V-s/NIR spectrophotometer. The PL spectra were obtained by using Jasco FP-6300 with an excitation wavelength of $453 \mathrm{~nm}$. The FITR transmittance spectra were derived by using Thermo Nicolet NEXUS470. The XRD were recorded by using PANalytical, X' Pert PRO. The field emission scanning electron microscope (SEM) images were performed by using JOEL JSM-6700F.

\section{Results and Discussion}

Figure 1 shows the transfer characteristics of the all-inkjetprinted OTFTs with various CNP concentrations. The threshold voltages $\left(V_{T}\right)$ of the OTFTs were obtained from the plot of the $V_{\mathrm{GS}}-I_{\mathrm{DS}}^{1 / 2}$ at saturation region by extrapolating the fitting line and locating the $x$-intercept, as shown in Figure 1(b). However, the switching behavior of the transistor degenerated, while 43 wt.\% CNP blended, as shown in Figure 1(a). 


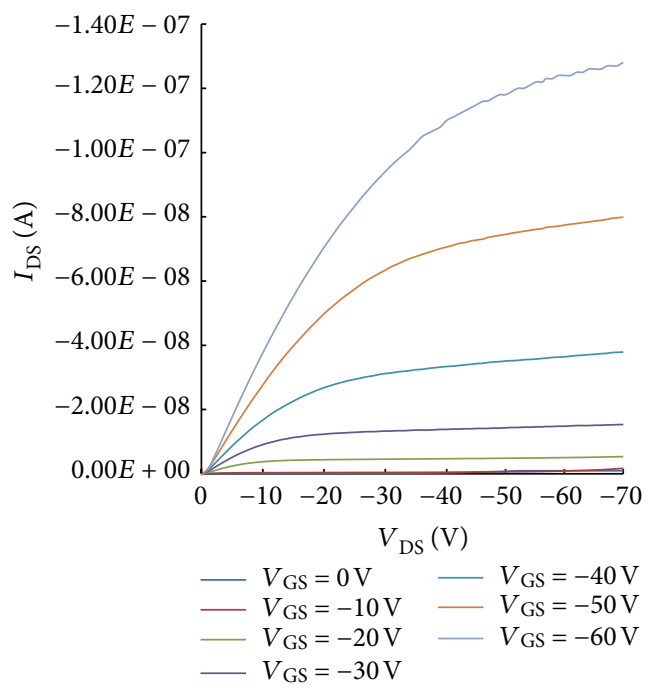

(a)

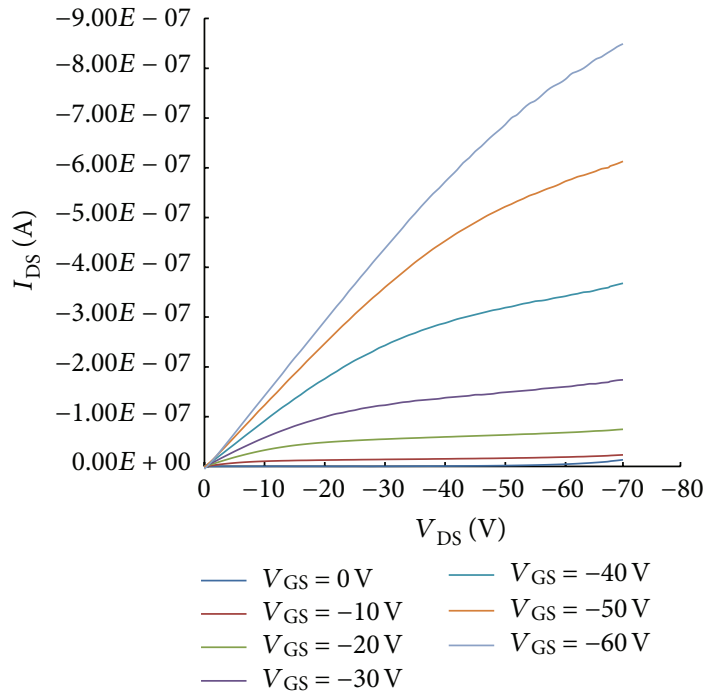

(c)

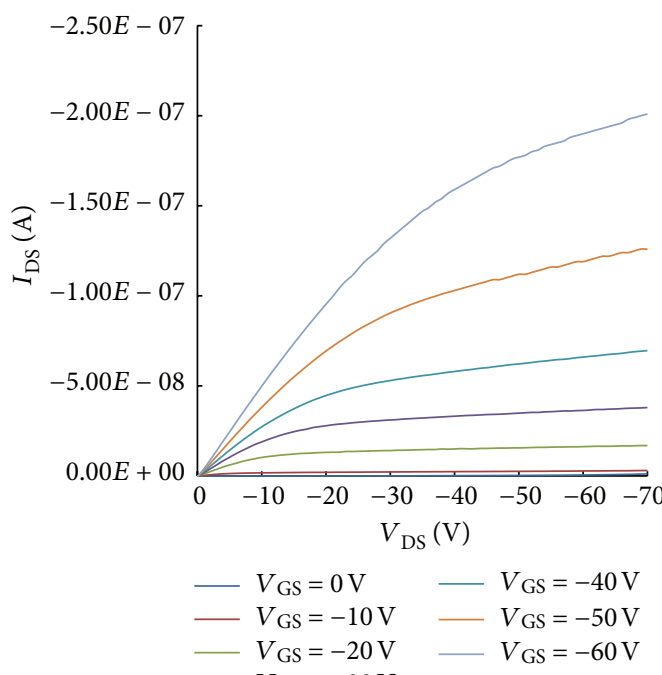

(b)

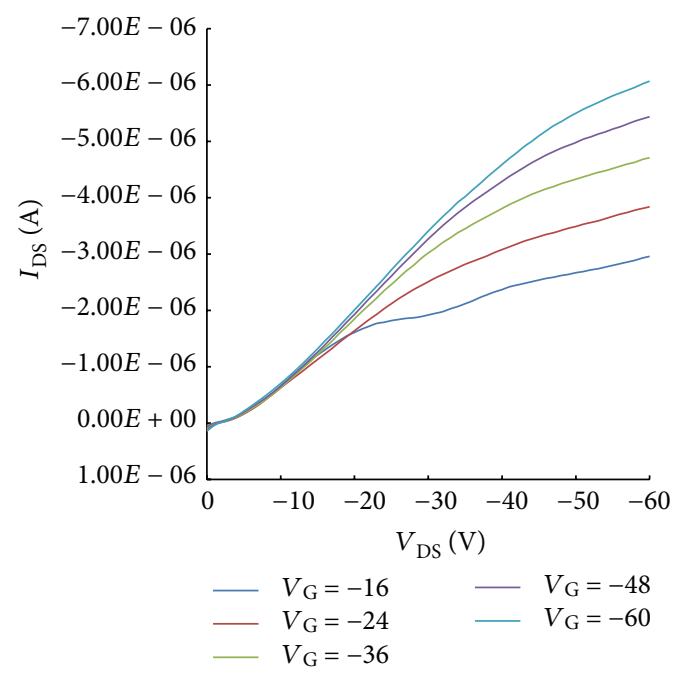

(d)

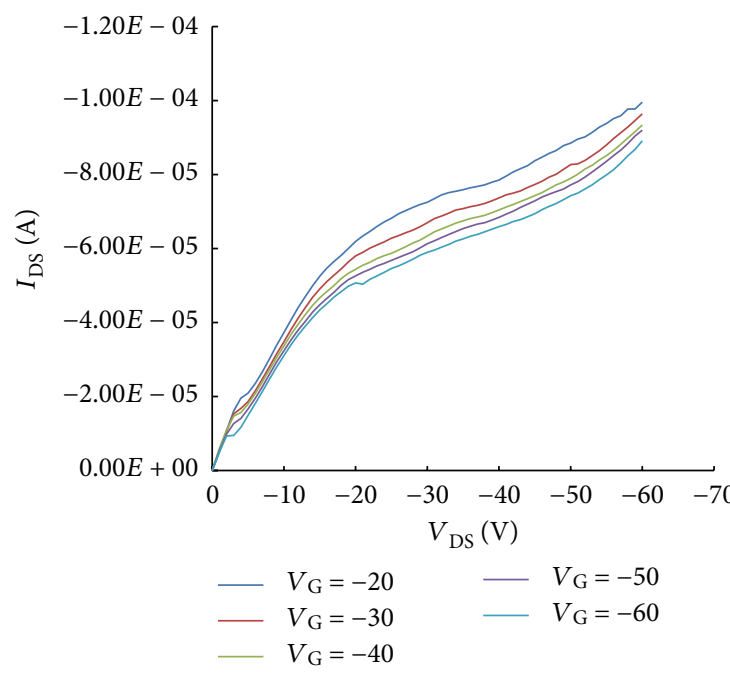

(e)

Figure 2: Output characteristics for (a) pristine P3HT, (b) CNP/P3HT = 1 wt.\%, (c) CNP/P3HT = 5 wt.\%, (d) CNP/P3HT = 10 wt. \%, and (e) $\mathrm{CNP} / \mathrm{P} 3 \mathrm{HT}=43 \mathrm{wt} . \%$ OTFTs. 
Because the CNP dominated the channel conductance, the $V_{T}$ of OTFT with $43 \mathrm{wt}$ \% CNP could not be defined.

To obtain the field-effect mobility, the output characteristics of the OTFTs are shown in Figure 2. Three kinds of methods were approached to calculate the average field-effect mobility accurately for different OTFTs. Because the OTFTs blended with 0 wt.\%, 1 wt.\%, and 5 wt.\% CNP exhibited saturation behavior (as shown in Figures 2(a)-2(c)), the fieldeffect mobility of such OTFTs was calculated in saturation region $\left(V_{\mathrm{DS}}=-70 \mathrm{~V}\right)$ by plotting the $V_{\mathrm{GS}}-I_{\mathrm{DS}}{ }^{1 / 2}$ and fitting the data to the equation $[12,14]$

$$
\mu=\frac{2 L}{W C_{i}}\left(\frac{\partial \sqrt{I_{D}}}{\partial V_{\mathrm{GS}}}\right)^{2},
$$

where the capacitance $C_{i}=11.0 \times 10^{-9} \mathrm{~F} \mathrm{~cm}^{-2}$. The OTFT with 10 wt.\% CNP did not present saturation behavior (as shown in Figure 2(d)) but was still modulated by the gate bias. Consequently, the average field-effect mobility was estimated in linear region $\left(V_{\mathrm{DS}}=-60 \mathrm{~V}\right)$ by using the equation [19]

$$
\mu=\frac{L}{W C_{i} V_{\mathrm{DS}}} \frac{\partial I_{\mathrm{DS}}}{\partial V_{\mathrm{GS}}} .
$$

As shown in Figure 2(e), at the same time, the OTFT with 43 wt.\% CNP had neither saturation behavior nor gatemodulation effect. First, the conductivity was derived from the channel length and cross-sectional area $(A=W \times t)$ by

$$
\sigma=\frac{I_{\mathrm{DS}}}{V_{\mathrm{DS}}} \frac{L}{A},
$$

where the thickness $t=100 \mathrm{~nm}$. Then the mobility could be estimated by [20]

$$
\mu=\frac{\sigma}{e p} .
$$

The electrical properties of the OTFTs including mobility, on/off ratio, and $V_{T}$ are summarized in Table 1 . The effective mobility $\left(\mu_{\text {eff }}\right)$ of OTFT ranges from around $10^{-4}$ to $10^{-2} \mathrm{~cm}^{2} / \mathrm{V}$-s, which is comparable to those of inkjet-printed P3HT OTFTs reported previously $[11,21]$. The $\mu_{\text {eff }}$ can be modeled by using percolation theory as described by the following equation $[22,23]$ :

$$
\mu_{\mathrm{eff}}=\mu_{\text {pristine-P3HT }}+\frac{\mu_{\text {blend-max }}}{1+\exp \left(\left(p_{C}-p\right) / C\right)},
$$

where the $\mu_{\text {pristine-P3HT }}$ was the intrinsic mobility of pristine P3HT; the maximum mobility $\left(\mu_{\text {blend-max }}\right)$ was obtained from the OTFT with highest CNP blending concentration (i.e., 43 wt.\%); $p$ is the blending concentration of CNP; the $p_{C}$ is percolation threshold; and $C$ is a fitting parameter. After fitting the effective mobility to (5), the following parameters were extracted: $p_{C}=7.5 \mathrm{wt} . \%$ and $C=1 \mathrm{wt} . \%$. The fitting result is plotted in Figure 3. When the concentration $p<p_{C}$, CNPs would induce a local electric field, which would let the P3HT near CNPs experience electric field larger than the applied gate bias. As a consequence, the carrier density

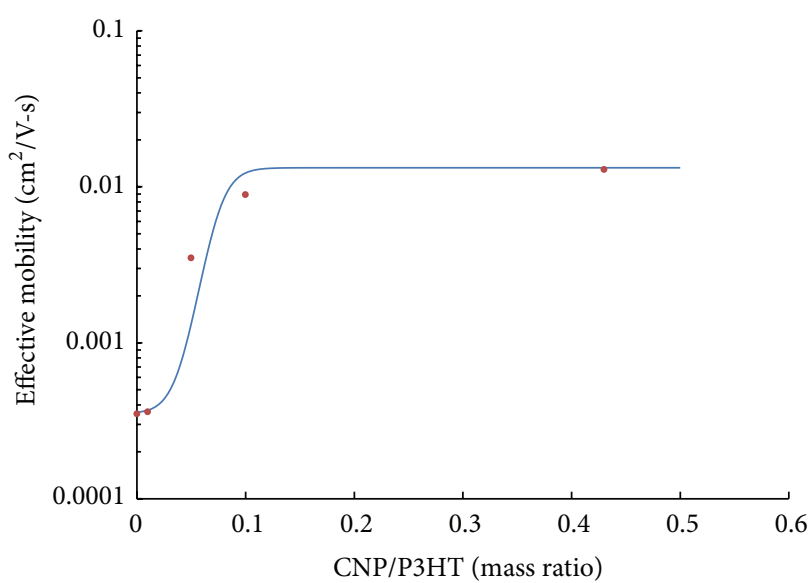

FIgURE 3: Percolation model for simulation and experimental data.

of P3HT can be increased [13] and the effective mobility of the OTFTs was also increased. When the CNP concentration is near or equal to the $p_{C}$, the percolation path is gradually formed, which is caused by the aggregation of CNPs. While the CNP concentration is above the $p_{C}$, the charge carrier would travel directly through the percolation path, and the CNPs will dominate the conductivity. It should be noted that the local electric field, which was induced by CNP, would also affect the threshold voltage of OTFTs. The threshold voltage was shifted from $-12.5 \mathrm{~V}$ (pristine P3HT) to $3 \mathrm{~V}(\mathrm{CNP} / \mathrm{P} 3 \mathrm{HT}$ $=10$ wt. $\%$ ), which increased with the CNP concentration. The similar phenomena and the field enhancement factor have also been reported $[16,17]$.

To investigate the mechanism of the improved performance, the contact resistance between the P3HT and the electrodes, poly(3,4-ethylenedioxythiophene)/ poly(styrenesulfonate) (PEDOT: PSS), was studied. In order to exam the electronic properties at the interface, the OTFTs were operated in linear region $\left(V_{\mathrm{DS}} \ll V_{\mathrm{GT}} ; V_{\mathrm{DS}}=-0.1 \mathrm{~V}\right.$; $V_{\mathrm{GT}}=V_{\mathrm{GS}}-V_{\mathrm{T}}=-5,-15,-25,-35,-45$, and $\left.-55 \mathrm{~V}\right)$ with different channel lengths $(L=20,60$, and $100 \mu \mathrm{m})$ and constant channel width $(W=800 \mu \mathrm{m})$. Figure 4 shows the on-resistance $\left(R_{\mathrm{on}}\right)$ as a function of channel length at fixed $V_{\mathrm{GT}}$ for pristine P3HT and CNP-blended OTFT. The $R_{\text {on }}$ can be represented by $R_{\text {on }}=R_{\mathrm{ch}}+R_{C}$, where $R_{\mathrm{ch}}$ represents the channel resistance and $R_{C}$ symbolizes the contact resistance. The contact resistance and channel resistance of OTFT with $L=20 \mu \mathrm{m}$ are summarized in Table 2. Figure 4 also shows that incorporating CNPs with $\mathrm{P} 3 \mathrm{HT}$ reduced the contact resistance and channel resistance by an average factor of two. These results suggested that incorporating CNPs could modulate the hole-injection barrier between the PEDOT and $\mathrm{P} 3 \mathrm{HT}$, which could reduce the contact resistance and result in a higher effective carrier injection $[14,24]$.

The morphology of the CNP/P3HT nanocomposites was observed by an optical microscope and SEM. Figure 5(a) shows the optical images in the channel region of OTFTs with 0 wt.\% CNP, 1 wt.\% CNP, 5 wt.\% CNP, and 10 wt.\% CNP. These images indicated that the CNPs aggregated when the concentration of CNP increased. For the detailed dispersion 


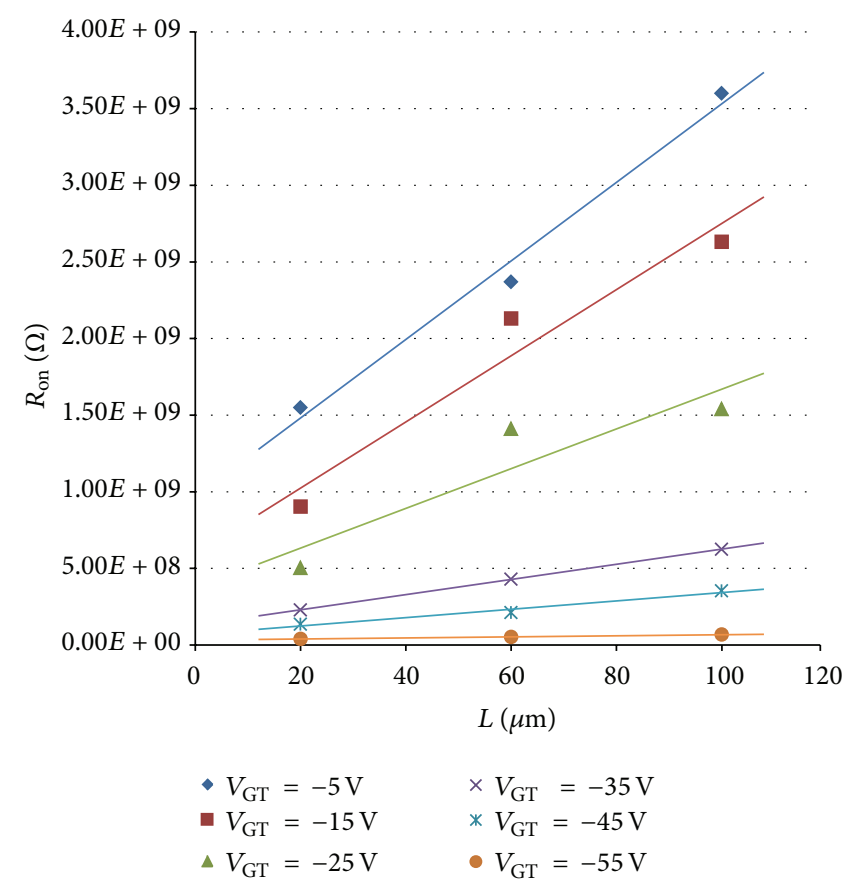

(a)

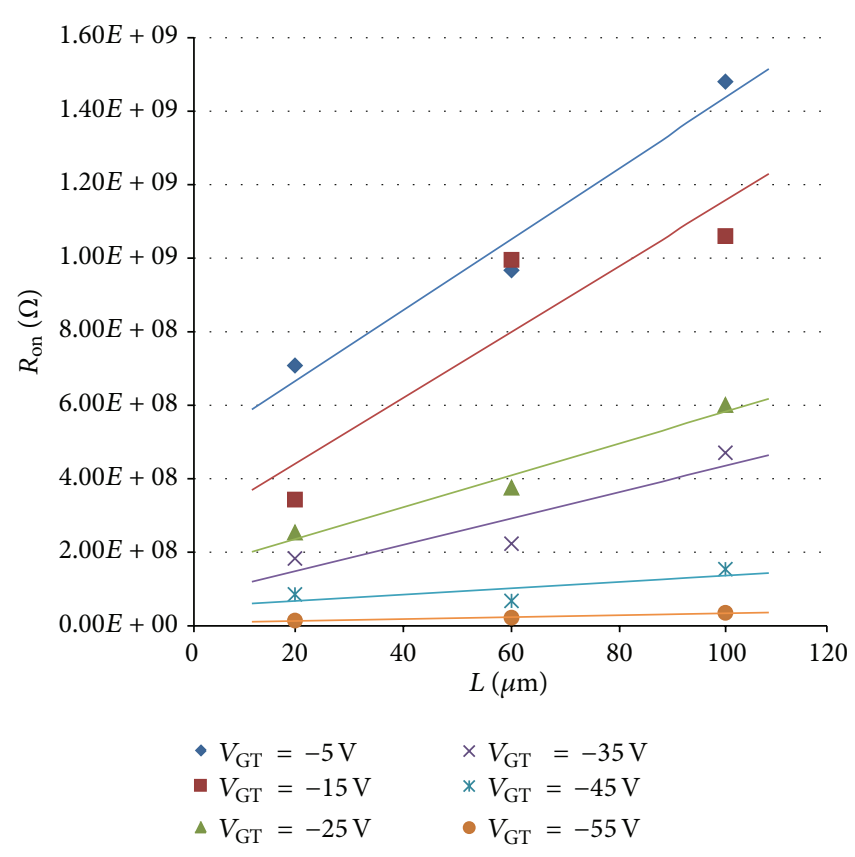

(b)

FIGURE 4: On resistance $\left(R_{\text {on }}\right)$ measurement as a function of channel length with various $V_{\mathrm{GT}}$ for (a) pristine $\mathrm{P} 3 \mathrm{HT}$ and $(\mathrm{b}) \mathrm{CNP} / \mathrm{P} 3 \mathrm{HT}=$ 5 wt.\% OTFTs.

TABLE 1: Electrical properties of fabricated OTFTs.

\begin{tabular}{lccccc}
\hline Blending concentration & Pristine P3HT & $\mathrm{CNP} / \mathrm{P} 3 \mathrm{HT}=1$ wt.\% & $\mathrm{CNP} / \mathrm{P} 3 \mathrm{HT}=5$ wt.\% & $\mathrm{CNP} / \mathrm{P} 3 \mathrm{HT}=10$ wt. \% & $\mathrm{CNP} / \mathrm{P} 3 \mathrm{HT}=43$ wt. $\%$ \\
\hline On/off ratio & $3.67 \times 10^{5}$ & $2.26 \times 10^{5}$ & $1.20 \times 10^{5}$ & $4.13 \times 10^{2}$ & 2.1 \\
$V_{T}(\mathrm{~V})$ & -12.5 & -10 & -7.5 & 3 & $\mathrm{n} / \mathrm{a}$ \\
$\mu\left(\mathrm{cm}^{2} \mathrm{~V}^{-1} \mathrm{~s}^{-1}\right)$ & 0.00035 & 0.00036 & 0.0035 & 0.0089 & 0.0123 \\
\hline
\end{tabular}

of the CNP/P3HT nanocomposite, the SEM images with various concentrations were performed in Figures 5(b)-5(f). As aforementioned, CNP improved the injection barrier and enhance the field-effect mobility at low blending ratio. When the blending concentration reaches a critical value, however, the CNPs form a percolation path, and the excess localized aggregations increase the off-current. As a consequence, the fabricated OTFT is turned into a resistor-like device and it might be further dominated by the electrical properties of CNPs. Based on the observations from Table 2 and Figure 5, small groups of CNP would aggregate, but the percolation path would not be connected when CNP/P3HT $<10$ wt.\%. When the CNPs concentration was up to $10 \mathrm{wt} \%$, some localized aggregations started to connect to each other. While $\mathrm{CNP} / \mathrm{P} 3 \mathrm{HT}=43 \mathrm{wt} . \%$, most of CNPs were aggregated and the electrical properties of OTFT were dominated by CNPs. In other words, the drain current of fabricated OTFT devices was not modulated by the gate bias.

Previous investigations in XRD spectra show the intensity of the (100) reflection, which is caused by the lamellar layer structure, reduced with the increasing amount of CNP [18]. This result indicated that adding CNP into $\mathrm{P} 3 \mathrm{HT}$ will disturb the crystal ordering of the organic semiconductor. In general, the decreasing of crystal ordering suppresses the carrier transportation. However, adding CNP into $\mathrm{P} 3 \mathrm{HT}$ improved the field-effect mobility of OTFT. To further explore the reason of this mobility enhancement, other analyses were executed.

The functional groups were identified by the absorption band of the FTIR spectra for P3HT and CNP/P3HT nanocomposite, as shown in Figure 6 . The band at $721 \mathrm{~cm}^{-1}$ is associated with the methyl rock of P3HT. The peak at $819 \mathrm{~cm}^{-1}$ is contributed by the aromatic C-H, out-of-plane. The band at $1377 \mathrm{~cm}^{-1}$ is assigned to methyl deformation. The band at $1457 \mathrm{~cm}^{-1}$ is assigned to the symmetric C-C stretching mode, and the $1509 \mathrm{~cm}^{-1}$ is assigned the antisymmetric $\mathrm{C}=\mathrm{C}$ stretching mode. We could mark the variation of the average conjugation length of $\mathrm{P} 3 \mathrm{HT}$ from the ratio between the intensity at $1509 \mathrm{~cm}^{-1}$ and $1457 \mathrm{~cm}^{-1}[25,26]$. If the relative intensity increases at $1509 \mathrm{~cm}^{-1}$, the average conjugation length will increase. From Figure 6, the intensity ratio is kept the same, so the average conjugation length of P3HT backbones did not change after adding CNPs, which means that the molecule structure of P3HT is maintained. Consequently, no new bonding was observed between CNPs and P3HT. 

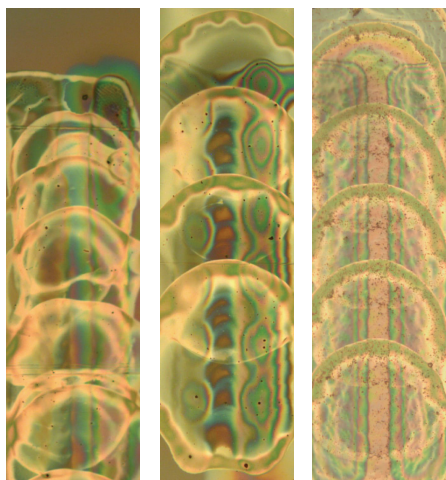

(a)

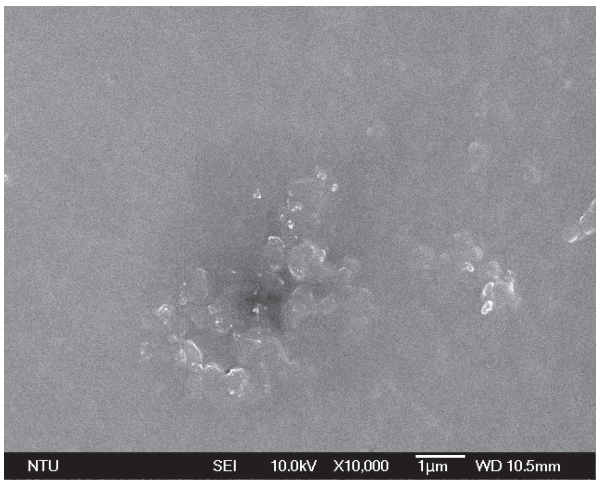

(c)

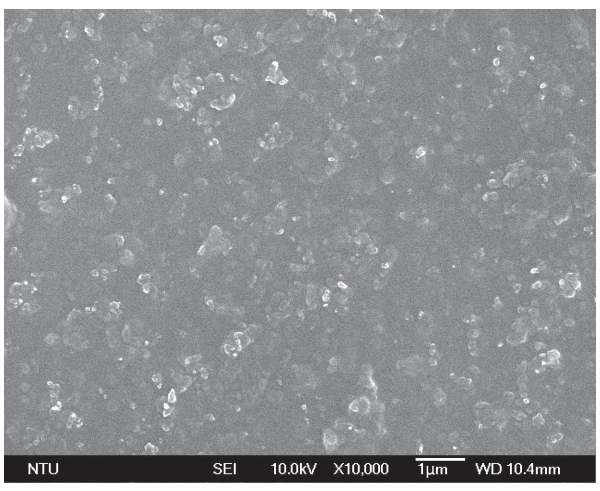

(e)

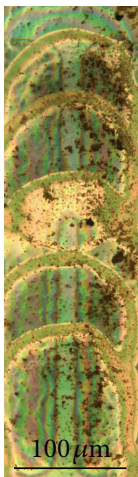

NTU

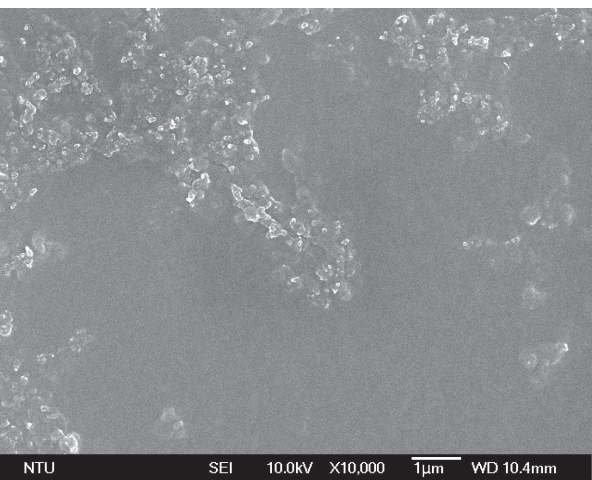

(d)

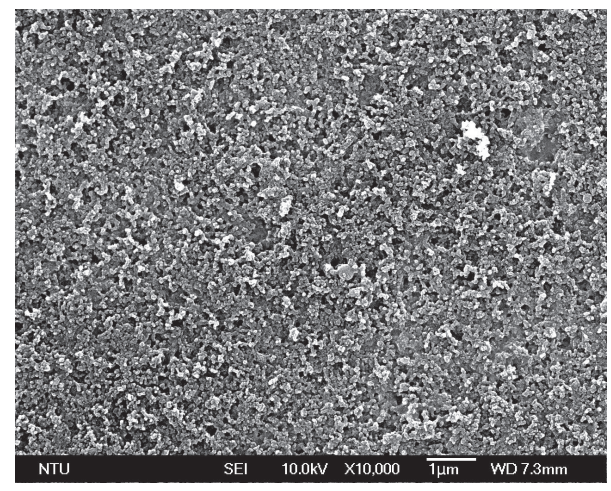

(f)

Figure 5: (a) Microscope images of channel region, from left to right, the CNP/P3HT, are 0 wt. $\%, 1 \mathrm{wt} . \%$, $5 \mathrm{wt} . \%$, and $10 \mathrm{wt} \%$, respectively. SEM images for (b) pristine P3HT, (c) CNP/P3HT = $1 \mathrm{wt} . \%$, (d) CNP/P3HT = 5 wt.\%, (e) CNP/P3HT = 10 wt. \%, and (f) CNP/P3HT = 43 wt. \%.

TABLE 2: Contact resistance and channel resistance analysis.

\begin{tabular}{|c|c|c|c|c|c|c|}
\hline$R_{C}(\Omega)$ & $V_{\mathrm{GT}}=-5 \mathrm{~V}$ & $V_{\mathrm{GT}}=-15 \mathrm{~V}$ & $V_{\mathrm{GT}}=-25 \mathrm{~V}$ & $V_{\mathrm{GT}}=-35 \mathrm{~V}$ & $V_{\mathrm{GT}}=-45 \mathrm{~V}$ & $V_{\mathrm{GT}}=-55 \mathrm{~V}$ \\
\hline P3HT & $1.00 \times 10^{9}$ & $5.00 \times 10^{8}$ & $2.50 \times 10^{8}$ & $1.25 \times 10^{8}$ & $7.50 \times 10^{7}$ & $2.50 \times 10^{7}$ \\
\hline CNP/P3HT (5 wt.\%) & $5.00 \times 10^{8}$ & $2.50 \times 10^{8}$ & $1.50 \times 10^{8}$ & $7.50 \times 10^{7}$ & $5.00 \times 10^{7}$ & $7.50 \times 10^{6}$ \\
\hline$R_{\mathrm{ch}}(\Omega),(L=20 \mu \mathrm{m})$ & $V_{\mathrm{GT}}=-5 \mathrm{~V}$ & $V_{\mathrm{GT}}=-15 \mathrm{~V}$ & $V_{\mathrm{GT}}=-25 \mathrm{~V}$ & $V_{\mathrm{GT}}=-35 \mathrm{~V}$ & $V_{\mathrm{GT}}=-45 \mathrm{~V}$ & $V_{\mathrm{GT}}=-55 \mathrm{~V}$ \\
\hline P3HT & $5.53 \times 10^{8}$ & $4.03 \times 10^{8}$ & $2.53 \times 10^{8}$ & $1.04 \times 10^{8}$ & $6.03 \times 10^{7}$ & $1.50 \times 10^{7}$ \\
\hline CNP/P3HT (5 wt.\%) & $2.08 \times 10^{8}$ & $2.00 \times 10^{8}$ & $1.03 \times 10^{8}$ & $5.00 \times 10^{7}$ & $3.50 \times 10^{7}$ & $6.43 \times 10^{6}$ \\
\hline
\end{tabular}




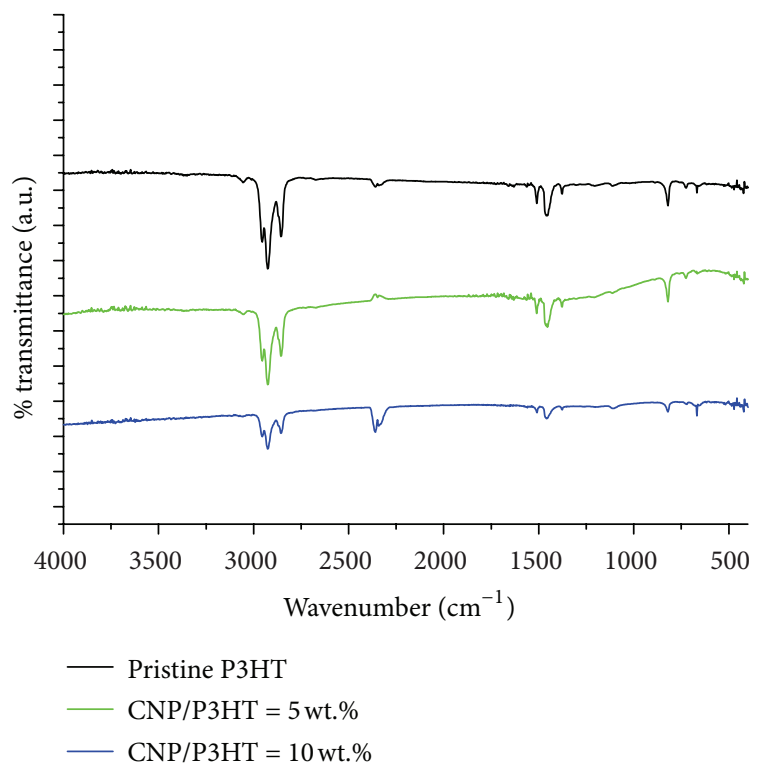

FIGURE 6: FTIR spectra of pristine P3HT, CNP/P3HT = 5 wt.\%, and $\mathrm{CNP} / \mathrm{P} 3 \mathrm{HT}=10$ wt. $\%$ thin films.

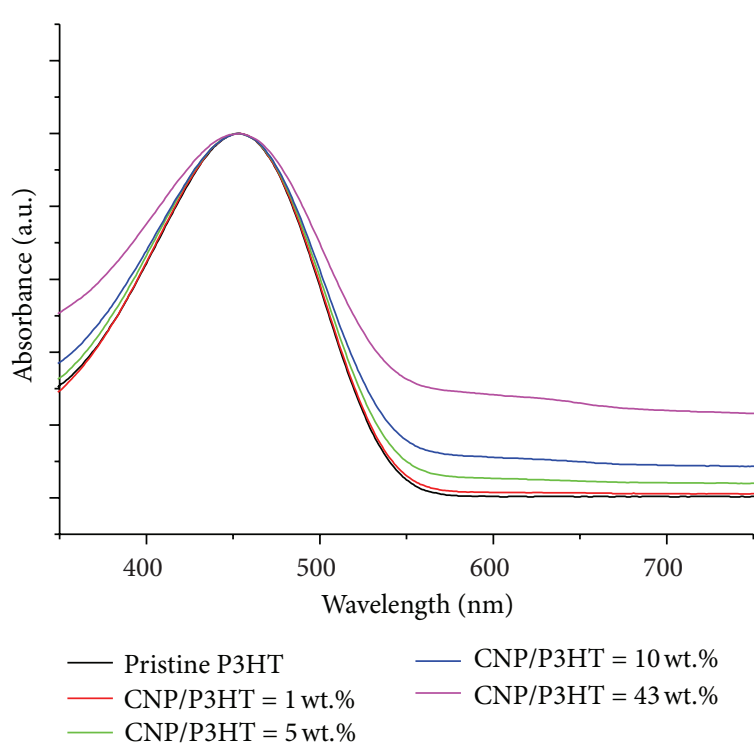

FIGURE 7: UV-Vis spectra of pristine P3HT, CNP/P3HT = $1 \mathrm{wt} . \%$, 5 wt. $\%, 10$ wt. $\%$, and 43 wt. $\%$.

To study interactions among the $\mathrm{P} 3 \mathrm{HT}$ chains in the $\mathrm{CNP} / \mathrm{P} 3 \mathrm{HT}$, furthermore, the UV-Vis spectra of $\mathrm{P} 3 \mathrm{HT}$ and $\mathrm{CNP} / \mathrm{P} 3 \mathrm{HT}$ nanocomposites are shown in Figure 7 . The absorption peak which located at $453 \mathrm{~nm}$ represented to the electron transition from the highest occupied molecular orbital (HOMO) to the lowest unoccupied molecular orbital (LUMO) of the P3HT $[27,28]$. Geng et al. reported that the $\pi$ electrons of the blended CNTs would interact with the conjugated polymers, which represent as the UV-Vis absorption peaks broadening [29]. The similar phenomenon could be observed in the spectra of CNP/P3HT. Figure 7 shows that the main absorption peak was broadened with the increasing amount of CNPs because of the $\pi-\pi$ interaction between the conjugated chain of the P3HT and the $\pi$ orbital of CNPs.

The LUMO-HOMO relaxation could be observed from the maximum emission peak $\left(\lambda_{\max }\right)$ of the PL spectra [29], as shown in Figure 8. The spectra mark the $\lambda_{\max }$ at 589, 586,572 , and $566 \mathrm{~nm}$ for $0 \mathrm{wt} . \%, 1 \mathrm{wt} . \%, 5 \mathrm{wt} . \%$, and $10 \mathrm{wt} . \%$ $\mathrm{CNP} / \mathrm{P} 3 \mathrm{HT}$, respectively. The main emission peak appeared small blueshift with the increasing concentration of the blended CNP. This is because the ground state energy of the composite material was lower than that of P3HT. This difference results in the increase of the energy gap of relaxation $[30,31]$. Another phenomenon that could be observed from the PL spectra is quenching effect. The PL quenching revealed that the CNPs may offer another decaying path which competing with the radiative relaxation and the quenching effect became more obvious with the CNPs concentration increased [30]. Both the blue shift and quenching effects illustrated that the charge transfers appeared from the LUMO of P3HT to CNPs [29-32]. Consequently, the CTC state formed in the $\mathrm{CNP} / \mathrm{P} 3 \mathrm{HT}$ composites and the energy level of the CTC state was between the work function of CNP and the HOMO of P3HT $[33,34]$.

According to the experiments shown in this paper, the blending CNP/P3HT would not modify the molecular structures of P3HT or CNPs, either adjust the intrinsic mobility of P3HT or CNPs. Therefore, three reasons for effective mobility enhancement by incorporating CNP/P3HT nanocomposites could be concluded: (1) local electric field enhancement resulted from the CNPs that will induce higher carrier density of P3HT, (2) adding CNPs in P3HT matrix would reduce the carrier injection barrier and improve the injection efficiency, and (3) the formation of the CTC would enhance the carrier transportation between CNPs and P3HT.

The band diagrams of CNP/P3HT illustrate the effect of the local electric field, as shown in Figure 9. When the negative gate bias is applied, p-type organic semiconductor will be operated in accumulation mode, as shown in Figure 9(b). The addition of CNPs will induce local electric field to drive the P3HT near CNPs experience larger gate bias than that of external applied. Therefore, the P3HT will induce more carriers and further increase the effective mobility. Second, the work functions are 5.2-5.3, 5.13, and $4.9 \mathrm{eV}$, respectively, for PEDOT, CNP, and P3HT [35-38]. Adding CNPs into P3HT matrix can reduce the injection barrier which was verified by contact resistance measurement. Third, according to the material analyses in this study, we proposed that the formation of CTC at the interface between P3HT and CNPs could assist the carrier transportation in the channel region to enhance the effective mobility.

\section{Conclusion}

Adding CNPs in P3HT matrix enhanced the effective mobility by a factor of 10 . The improvement of the contact resistance resulted from the injection barrier decreased at the interface between PEDOT and P3HT by cooperating CNPs into P3HT matrix. On the other hand, the improvement of the channel resistance is caused by the formation of CTC. According to the percolation model, local electric field is enhanced, while 


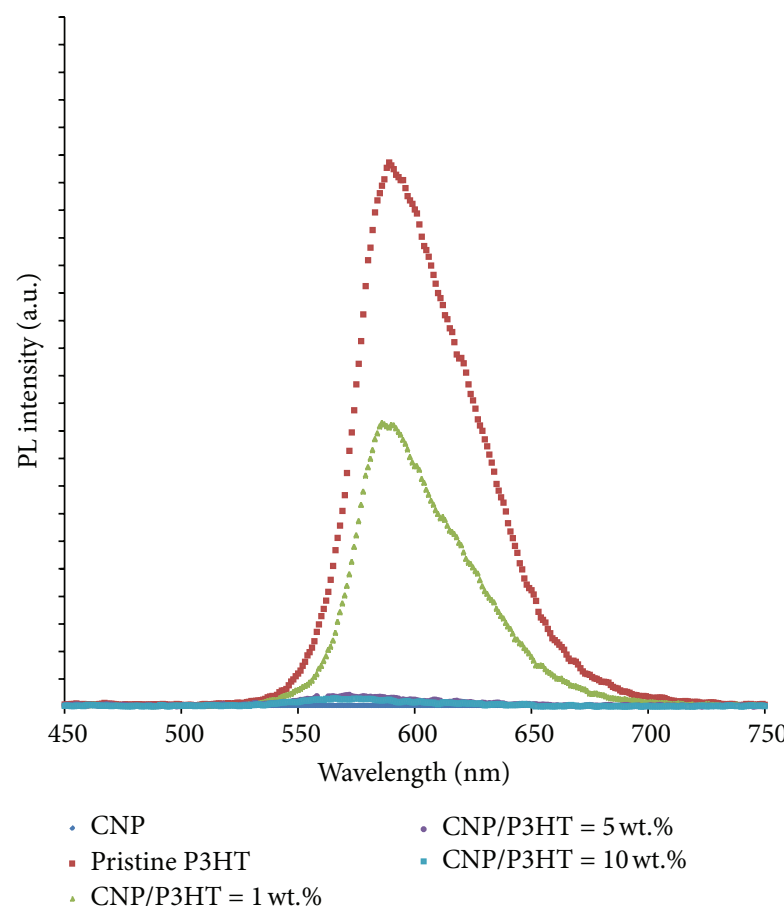

(a)

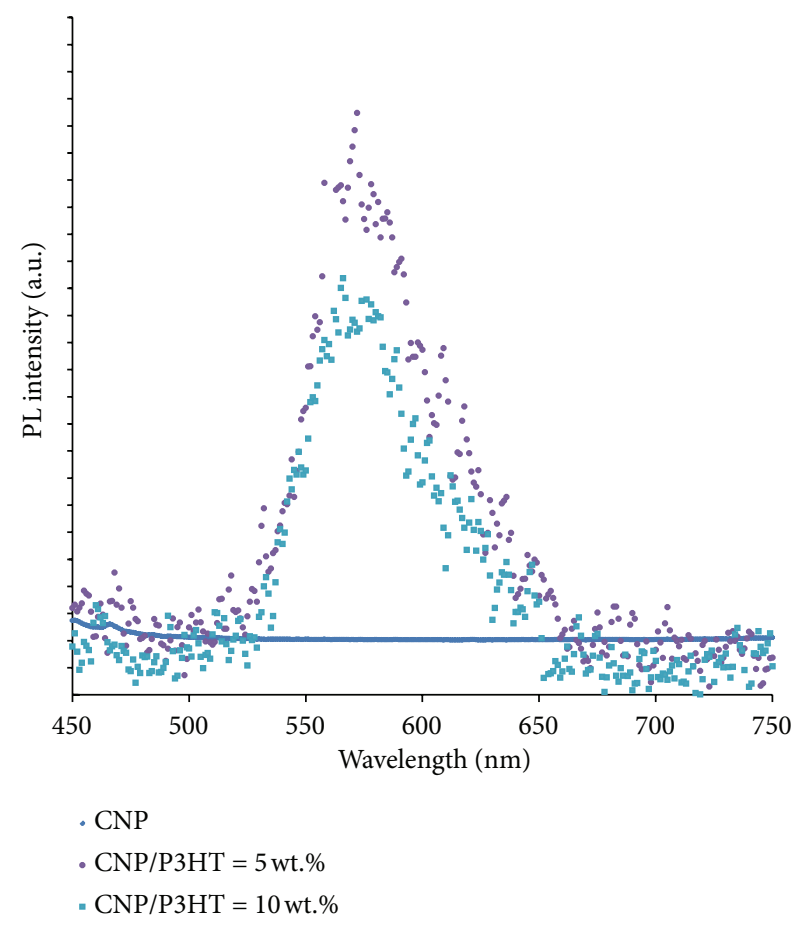

(b)

Figure 8: Photoluminescence spectra of CNPs, pristine P3HT, CNP/P3HT = 1 wt.\%, 5 wt.\%, and 10 wt.\%.

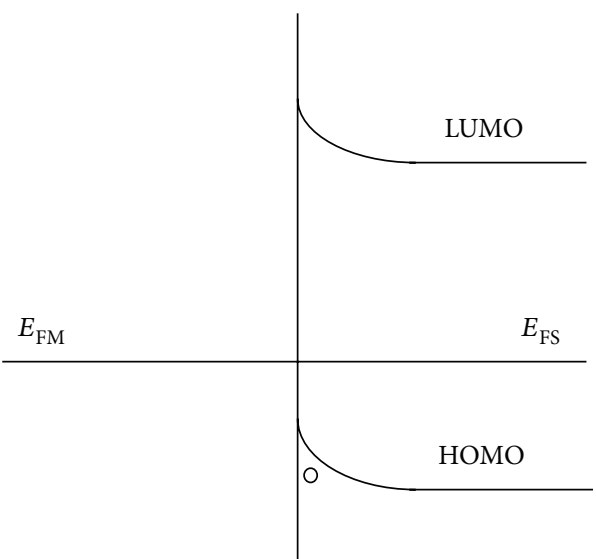

(a)

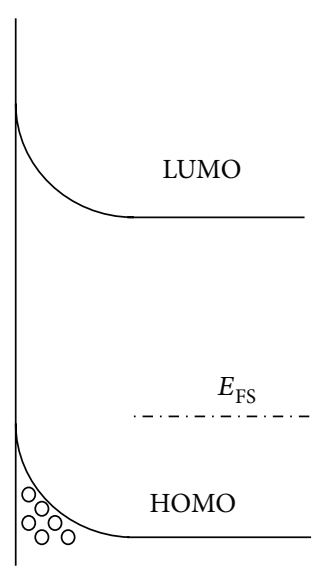

(b)

FIGURE 9: Energy band diagrams for (a) equilibrium condition with $V_{\mathrm{GS}}=0 \mathrm{~V}$ and (b) accumulation mode with $V_{\mathrm{GS}}<0 \mathrm{~V}$.

the blending concentration is less than the threshold concentration. This enhancement can induce more carriers of $\mathrm{P} 3 \mathrm{HT}$ near CNPs to increase the effective mobility. If CNP concentration is near $p_{C}$, the percolation path is gradually formed. The local field enhancement will gradually diminish due to the CNPs aggregation. After the percolation path formed, charge will transport directly through the path. The percolation paths formed from the considerable aggregations of CNPs will dominate the electrical properties and degrade transistor characteristics of the OTFT. In this work, the basis of CNP/P3HT blended system has been analyzed for further applications in OTFT.

\section{Conflict of Interests}

The authors declare that there is no conflict of interests regarding the publication of this paper.

\section{Acknowledgments}

This work is supported by National Science Council (NSC 101-2628-E-002-022-MY3 and NSC 101-2911-I-002-001) and Intel-NTU Connected Context Computing Center (NTU102R7501). 


\section{References}

[1] H. Sirringhaus, T. Kawase, R. H. Friend et al., "High-resolution inkjet printing of all-polymer transistor circuits," Science, vol. 290, no. 5499, pp. 2123-2126, 2000.

[2] W. Nie, R. Coffin, J. Liu et al., "Exploring spray-coating techniques for organic solar cell applications," International Journal of Photoenergy, vol. 2012, Article ID 175610, 7 pages, 2012.

[3] K. R. Choudhury, J. Lee, N. Chopra et al., "Highly efficient hole injection using polymeric anode materials for small-molecule organic light-emitting diodes," Advanced Functional Materials, vol. 19, no. 3, pp. 491-496, 2009.

[4] C.-H. Lee, W.-Y. Chuang, S.-H. Lin, W.-J. Wu, and C.-T. Lin, "A printable humidity sensing material based on conductive polymer and nanoparticles composites," Japanese Journal of Applied Physics, vol. 52, no. 5, Article ID 05DA08, 4 pages, 2013.

[5] C.-T. Lin, C.-H. Hsu, C.-H. Lee, and W.-J. Wu, "Inkjetprinted organic field-effect transistor by using composite semiconductor material of carbon nanoparticles and poly(3-hexylthiophene)," Journal of Nanotechnology, vol. 2011, Article ID 142890, 7 pages, 2011.

[6] S. A. DiBenedetto, A. Facchetti, M. A. Ratner, and T. J. Marks, "Molecular self-assembled monolayers and multilayers for organic and unconventional inorganic thin-film transistor applications," Advanced Materials, vol. 21, no. 14-15, pp. 14071433, 2009.

[7] D. Boudinet, M. Benwadih, Y. Qi et al., "Modification of gold source and drain electrodes by self-assembled monolayer in staggered n- and p-channel organic thin film transistors," Organic Electronics, vol. 11, no. 2, pp. 227-237, 2010.

[8] L. Jiang, J. Zhang, D. Gamota, and C. G. Takoudis, "Enhancement of the field-effect mobility of solution processed organic thin film transistors by surface modification of the dielectric," Organic Electronics, vol. 11, no. 2, pp. 344-350, 2010.

[9] M. W. Lee and C. K. Song, "Oxygen plasma effects on performance of pentacene thin film transistor," Japanese Journal of Applied Physics 1, vol. 42, no. 7, pp. 4218-4221, 2003.

[10] A. Wang, I. Kymissis, V. Bulović, and A. I. Akinwande, "Engineering density of semiconductor-dielectric interface states to modulate threshold voltage in OFETs," IEEE Transactions on Electron Devices, vol. 53, no. 1, pp. 9-13, 2006.

[11] J. A. Lim, J. H. Kim, L. Qiu et al., "Inkjet-printed single-droplet organic transistors based on semiconductor nanowires embedded in insulating polymers," Advanced Functional Materials, vol. 20, no. 19, pp. 3292-3297, 2010.

[12] Y. J. Song, J. U. Lee, and W. H. Jo, "Multi-walled carbon nanotubes covalently attached with poly(3-hexylthiophene) for enhancement of field-effect mobility of poly(3-hexylthiophene)/multi-walled carbon nanotube composites," Carbon, vol. 48, no. 2, pp. 389-395, 2010.

[13] S. H. Liu, S. C. B. Mannsfeld, M. C. Lemieux, H. W. Lee, and Z. N. Bao, "Organic semiconductor-carbon nanotube bundle bilayer field effect transistors with enhanced mobilities and high on/off ratios," Applied Physics Letters, vol. 92, no. 5, Article ID 053306, 2008.

[14] Y. D. Park, J. A. Lim, Y. Jang et al., "Enhancement of the fieldeffect mobility of poly(3-hexylthiophene)/functionalized carbon nanotube hybrid transistors," Organic Electronics, vol. 9, no. 3, pp. 317-322, 2008.

[15] J. Tsukamoto, J. Mata, and T. Matsuno, "Organic field effect transistors using composites of semiconductive polymers and single-walled carbon nanotubes," Japanese Journal of Applied Physics 2, vol. 46, no. 17-19, pp. L396-L398, 2007.

[16] X. Q. Wang, M. Wang, P. M. He, Y. B. Xu, and Z. H. Li, "Model calculation for the field enhancement factor of carbon nanotube," Journal of Applied Physics, vol. 96, no. 11, pp. 6752-6755, 2004.

[17] A. Ahmad and V. K. Tripathi, "Model calculation of the scanned field enhancement factor of CNTs," Nanotechnology, vol. 17, no. 15, pp. 3798-3801, 2006.

[18] C.-T. Lin, C.-H. Hsu, I.-R. Chen, C.-H. Lee, and W.-J. Wu, "Enhancement of carrier mobility in all-inkjet-printed organic thin-film transistors using a blend of poly(3-hexylthiophene) and carbon nanoparticles," Thin Solid Films, vol. 519, no. 22, pp. 8008-8012, 2011.

[19] S. W. Bae, K. Kim, Y. D. Han et al., "Percolation threshold related to field-effect transistors using thin multi-walled carbon nanotubes composites," Synthetic Metals, vol. 159, no. 19-20, pp. 2034-2037, 2009.

[20] J. Macutkevic, P. Kuzhir, A. Paddubskaya et al., "Electrical transport in carbon black-epoxy resin composites at different temperatures," Journal of Applied Physics, vol. 114, no. 3, Article ID 033707, 2013.

[21] P. Y. Lo, P. W. Li, Z. W. Pei, J. Hou, and Y. J. Chan, "Enhanced P3HT OTFT transport performance using double gate modulation scheme," IEEE Electron Device Letters, vol. 30, no. 6, pp. 629-631, 2009.

[22] J. Smith, M. Heeney, I. McCulloch et al., "Percolation behaviour in high mobility p-channel polymer/small-molecule blend organic field-effect transistors," Organic Electronics, vol. 12, no. 1, pp. 143-147, 2011.

[23] D. M. Russell, C. J. Newsome, S. P. Li, T. Kugler, M. Ishida, and T. Shimoda, "Blends of semiconductor polymer and small molecular crystals for improved-performance thin-film transistors," Applied Physics Letters, vol. 87, no. 22, Article ID 222109, 2005.

[24] G. W. Hsieh, F. M. Li, P. Beecher et al., "High performance nanocomposite thin film transistors with bilayer carbon nanotube-polythiophene active channel by ink-jet printing," Journal of Applied Physics, vol. 106, no. 12, Article ID 123706, 2009.

[25] D. E. Motaung, G. F. Malgas, C. J. Arendse, S. E. Mavundla, and D. Knoesen, "Structural and photo-physical properties of spincoated poly(3-hexylthiophene) thin films," Materials Chemistry and Physics, vol. 116, no. 1, pp. 279-283, 2009.

[26] D. E. Motaung, G. F. Malgas, C. J. Arendse, S. E. Mavundla, C. J. Oliphant, and D. Knoesen, "Thermal-induced changes on the properties of spin-coated P3HT:C60 thin films for solar cell applications," Solar Energy Materials and Solar Cells, vol. 93, no. 9, pp. 1674-1680, 2009.

[27] J. H. Wu, G. T. Yue, Y. M. Xiao et al., "An ultraviolet responsive hybrid solar cell based on titania/poly(3-hexylthiophene)," Scientific Reports, vol. 3, article 1283, 2013.

[28] V. Shrotriya, J. Ouyang, R. J. Tseng, G. Li, and Y. Yang, "Absorption spectra modification in poly(3-hexylthiophene):methanofullerene blend thin films," Chemical Physics Letters, vol. 411, no. 1-3, pp. 138-143, 2005.

[29] J. X. Geng, B. S. Kong, S. B. Yang et al., "Effect of SWNT defects on the electron transfer properties in P3HT/SWNT hybrid materials," Advanced Functional Materials, vol. 18, no. 18, pp. 2659-2665, 2008.

[30] B. K. Kuila, S. Malik, S. K. Batabyal, and A. K. Nandi, "Insitu synthesis of soluble poly(3-hexylthiophene)/multiwalled 
carbon nanotube composite: morphology, structure, and conductivity," Macromolecules, vol. 40, no. 2, pp. 278-287, 2007.

[31] M. T. Khan, R. Bhargav, A. Kaur, S. K. Dhawan, and S. Chand, "Effect of cadmium sulphide quantum dot processing and post thermal annealing on P3HT/PCBM photovoltaic device," Thin Solid Films, vol. 519, no. 3, pp. 1007-1011, 2010.

[32] V. Dutta and D. Verma, "Dispersion of $\mathrm{CdX}(\mathrm{X}=\mathrm{Se}, \mathrm{Te})$ nanoparticles in P3HT conjugated polymer," Journal of Renewable and Sustainable Energy, vol. 1, no. 2, Article ID 023107, 2009.

[33] J. J. Benson-Smith, L. Goris, K. Vandewal et al., "Formation of a ground-state charge-transfer complex in polyfluorene/[6,6]phenyl-C61 butyric acid methyl ester (PCBM) blend films and its role in the function of polymer/PCBM solar cells," Advanced Functional Materials, vol. 17, no. 3, pp. 451-457, 2007.

[34] I. Haeldermans, K. Vandewal, W. D. Oosterbaan et al., "Groundstate charge-transfer complex formation in hybrid poly(3-hexyl thiophene):titanium dioxide solar cells," Applied Physics Letters, vol. 93, no. 22, Article ID 223302, 2008.

[35] X. W. Sun, J. Z. Huang, J. X. Wang, and Z. Xu, "A zno nanorod inorganic/organic heterostructure light-emitting diode emitting at 342 nm," Nano Letters, vol. 8, no. 4, pp. 1219-1223, 2008.

[36] D. A. Rider, B. J. Worfolk, K. D. Harris et al., "Stable inverted polymer/fullerene solar cells using a cationic polythiophene modified PEDOT:PSS cathodic interface," Advanced Functional Materials, vol. 20, no. 15, pp. 2404-2415, 2010.

[37] T. J. Fabish, "The dependence of the work function of carbon black on surface acidity," Journal of Colloid and Interface Science, vol. 62, no. 1, pp. 16-23, 1977.

[38] A. Liscio, G. P. Veronese, E. Treossi et al., "Charge transport in graphene-polythiophene blends as studied by Kelvin Probe Force Microscopy and transistor characterization," Journal of Materials Chemistry, vol. 21, no. 9, pp. 2924-2931, 2011. 

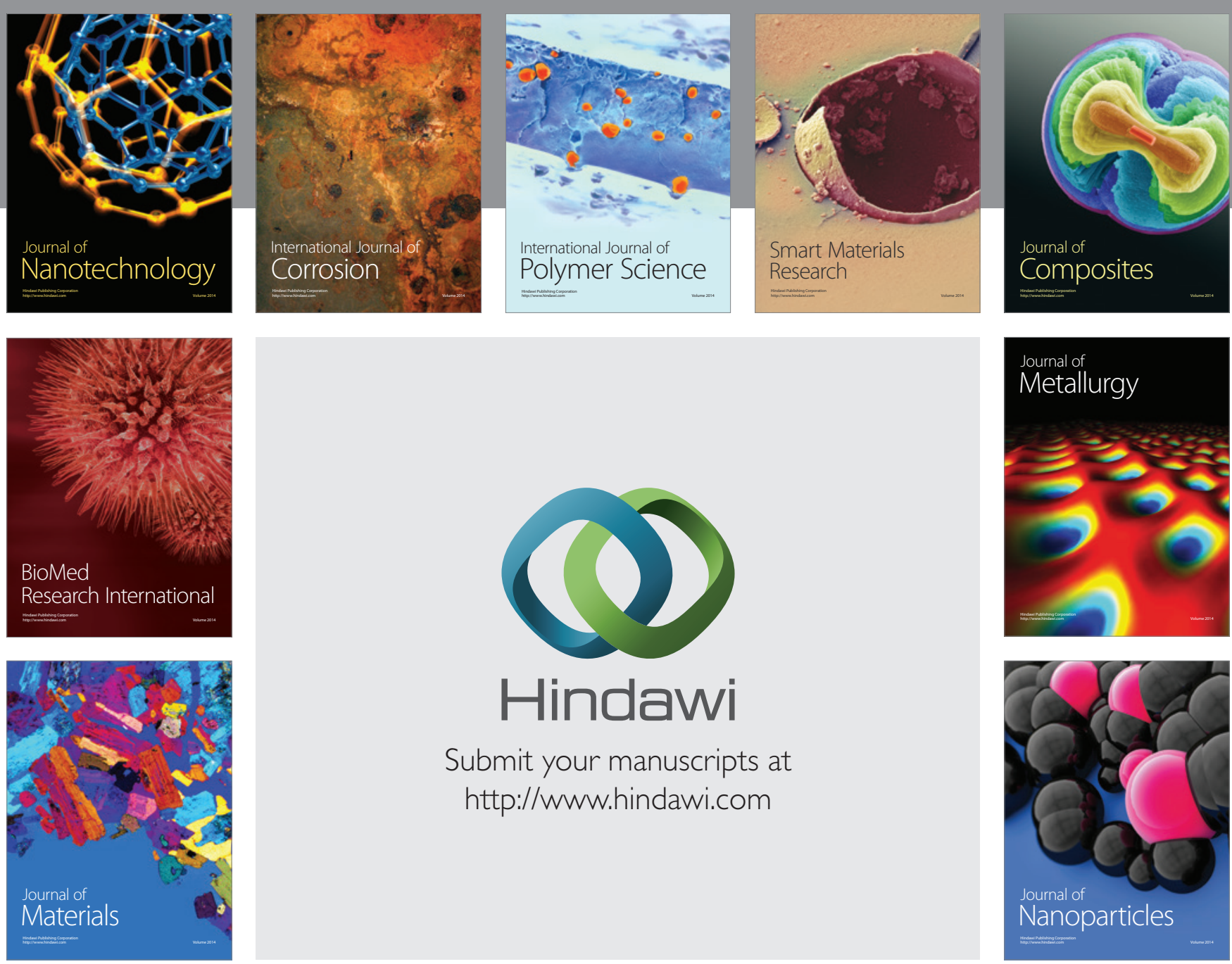

Submit your manuscripts at http://www.hindawi.com
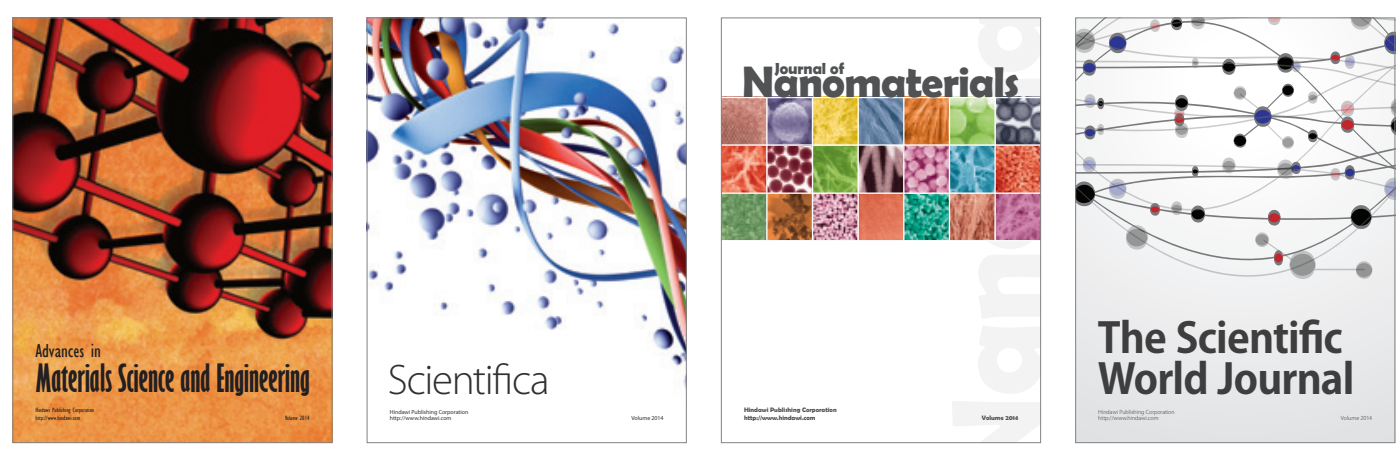

\section{The Scientific World Journal}
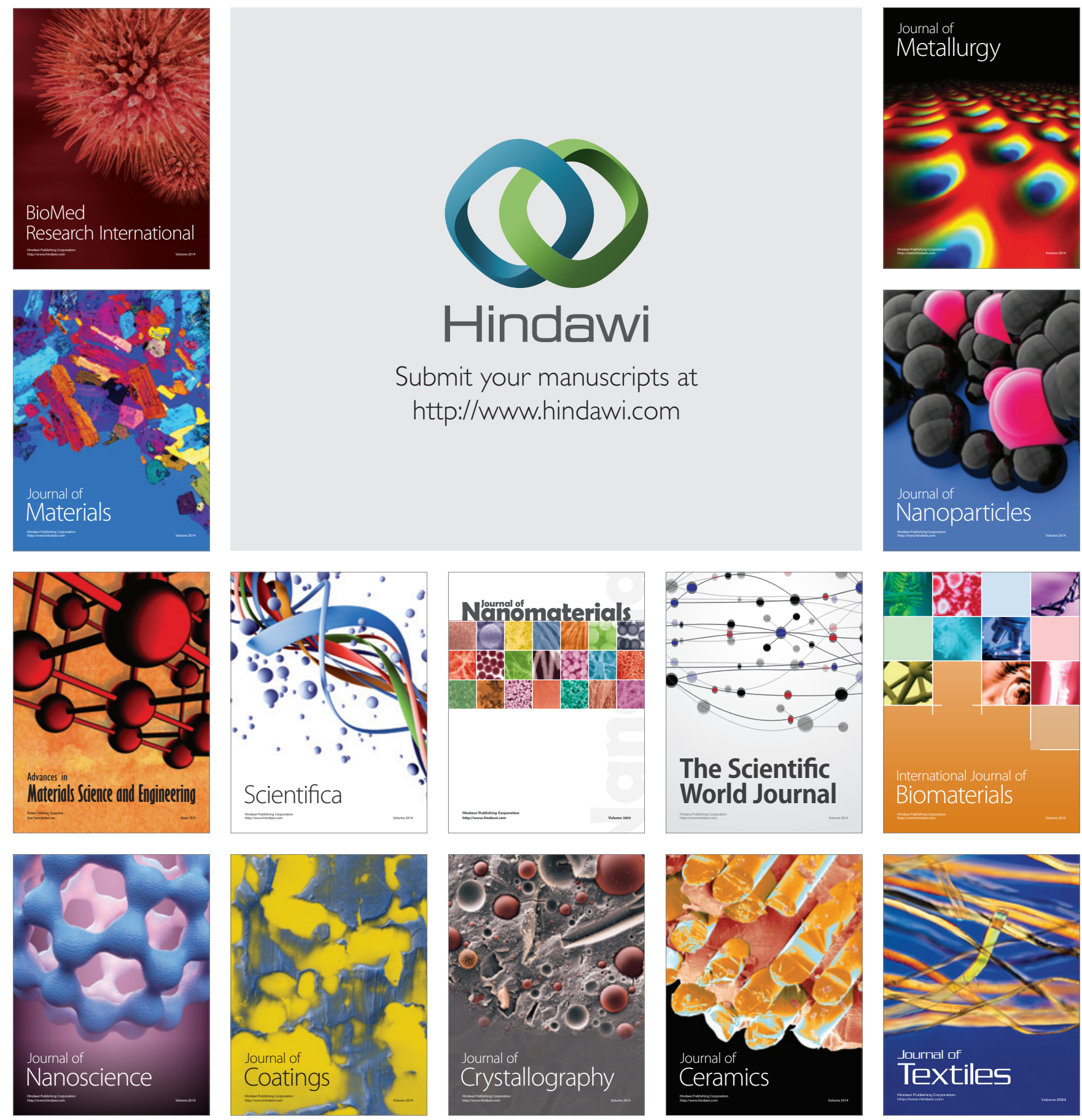